\title{
ANALISIS KELAYAKAN FINANSIAL PABRIK PENGGILINGAN BERAS ORGANIK "BOTANIK" (Studi Kasus Unit Processing Padi Organik Tani Mandiri I di Desa Lombok Kulon Kecamatan Wonosari Kabupaten Bondowoso)
}

\author{
Iftitah Hevi Riyanti ${ }^{1}$, Jabal Tarik Ibrahim ${ }^{2}$, Istis Baroh ${ }^{3}$ \\ ${ }^{1}$ Program Studi Agribisnis, Fakultas Pertanian Peternakan, Universitas Muhammadiyah Malang, Jalan \\ Raya Tlogomas No. 246, Malang, Indonesia \\ ${ }^{2,3}$ Program Studi Agribisnis, Fakultas Pertanian Peternakan, Universitas Muhammadiyah Malang, Jalan \\ Raya Tlogomas No. 246, Malang, Indonesia \\ Email korespondensi: $\underline{\text { fttitah@gmail.com }}$
}

\begin{abstract}
Organic rise is a rice which produce organically from paddy without using fertilizer and chemical perticides. The market demand on organic rice has increased drastically and effected on promising market prospect. Lombok Kulon village is one of the area di Bondowoso district has been applied organic farming on organic rice. Tani mandiri 1 is one of farmer group who are cultivating organic rice with the certificate. The subject of research was taken at Lombok Kulon village, Wonosari regency, Bondowoso district. The method of research was descriptive qualitative with purposive sampling. The objectives of the research are: (1) to analyze the financial structure; (2) To know the criteria of financial feasibility. The quantitave analysis is purposed to analyze the aspects of financial which are cash flow, NPV (Net Present Value), IRR (Internal Rate of Return), Net B/C Ratio, Payback Period and sensitivity analysis financial. The research showed that Unit Processing Padi Organik Tani Mandiri I was a viable unit based on the result of financial analysis. It was proved by NPV score which was Rp. 1.456 .180 .006 with $6 \%$ of discount rate, the score of Net B/C Ratio was 1,65 or more than (>) 1, and IRR score was $23,80 \%$ or more than (>) $6 \%$ of bank interest rate.
\end{abstract}

Keywords: Organic rice, Feasibility, Financial

\section{INTISARI}

Beras organik adalah beras yang diproduksi secara organik dari padi tanpa menggunakan pupuk dan pertisida kimia. Permintaan pasar terhadap beras organik telah meningkat secara drastis dan berdampak pada prospek pasar yang menjanjikan. Desa Lombok Kulon adalah salah satu daerah di Kabupaten Bondowoso yang telah menerapkan pertanian organik pada beras organik. Tani mandiri 1 adalah salah satu kelompok tani yang menanam padi organik dengan sertifikat. Subjek penelitian diambil di Desa Lombok Kulon, Kabupaten Wonosari, Kabupaten Bondowoso. Metode penelitian adalah deskriptif kualitatif dengan purposive sampling. Tujuan dari penelitian ini adalah: (1) untuk menganalisis struktur keuangan; (2) Untuk mengetahui kriteria kelayakan finansial. Analisis kuantitatif bertujuan untuk menganalisis aspek-aspek keuangan yaitu arus kas, NPV (Net Present Value), IRR (Internal Rate of Return), Rasio B / C Bersih, Periode Payback dan analisis sensitivitas keuangan. Penelitian menunjukkan bahwa Unit Pemrosesan Padi Organik Tani Mandiri I adalah unit yang layak berdasarkan hasil analisis keuangan. Itu dibuktikan dengan skor NPV yaitu Rp. 1.456.180.006 dengan 6\% dari tingkat diskonto, skor Net B / C Ratio adalah 1,65 atau lebih dari (>) 1, dan skor IRR adalah 23,80\% atau lebih dari (>) 6\% dari suku bunga bank.

Kata kunci: Beras organik, Kelayakan, Keuangan

\section{PENDAHULUAN}

Padi merupakan bahan baku dari beras, dimana beras merupakan kebutuhan dasar yang sangat penting bagi kehidupan manusia. Indonesia merupakan salah satu negara terbesar di dunia yang penduduknya mengkonsumsi beras sebagai makanan pokoknya. Kebutuhan akan pangan yakni beras di Indonesia terus menerus meningkat seiring dengan pertambahan jumlah penduduk. Pertambahan jumlah penduduk ini tidak diimbangi 
dengan peningkatan produksi pangan sehingga terjadi kekurangan pangan. Keadaan ini memberi pemikiran baru yang kemudian lahirlah revolusi hujau. Revolusi hijau merupakan upaya meningkatkan produksi pangan melalui usaha pengembangan teknologi pertanian. Kegiatan pertanian modern ini meliputi penggunaan bibit unggul, penggunaan pupuk kimia, mekanisasi pertanian, dan penyuluhan pertanian secara massal.

Revolusi hijau berkembang pesat dan mampu mencukupi kebutuhan pangan penduduk dunia. Hasilnya pada tahun 1984 Indonesia berhasil menjadi negara yang berswasembada pangan. Pada kenyataannya, adanya revolusi hijau justru berdampak negatif, yaitu meningkatkan penggunaan pupuk dan pestisida kimia. Dampak lain dari penggunaan pestisida kimia dapat mencemari lingkungan dan menyebabkan keracunan pada manusia (Sriyanto, 2010). Telah kita ketahui saat ini, terjadi penurunan kualitas produksi beras di Indonesia yang disebabkan oleh dampak negatif dari adanya revolusi hijau. Dampaknya tidak hanya terjadi penurunan kualitas produksi tetapi juga berdampak terhadap kesehatan masyarakat sebagai konsumen.

Pertanian Organik merupakan suatu sistem pertanian yang didesain dan dikelola sedemikian rupa sehingga mampu menciptakan produktivitas yang berkelanjutan. Prinsip pertanian organik yaitu tidak menggunakan atau membatasi penggunaan pupuk anorganik serta harus mampu menyediakan hara bagi tanaman dan mengendalikan serangan hama dengan cara lain diluar cara konvensional yang biasa dilakukan.

Masyarakat semakin sadar bahwa penggunaan bahan - bahan kimia non - alami , seperti pupuk dan pestisida kimia sintesis dalam produksi pertanian ternyata berdampak negatif terhadap kesehatan manusia dan lingkungan hidup. Masyarakat mulai beralih mengonsumsi beras organik sehingga saat ini permintaan beras organik sudah mulai meningkat. Permintaan beras organik yang meningkat drastis ini menjadi peluang besar bagi para petani khususnya petani yang menerapkan sistem pertanian organik. Beras organik merupakan salah satu produk pangan yang memiliki peluang untuk dikembangkan dalam suatu sistem agribisnis. Pengembangan agribisnis ramah lingkungan merupakan agribisnis yang dari segi perencanaan usaha telah memperhitungkan dampak terhadap alam secara berkelanjutan.

Usaha penggilingan padi merupakan suatu mata rantai usaha pengolahan gabah menjadi beras dan sebagai pelengkap suplai beras dalam sistem perekonomian masyarakat Indonesia. Usaha penggilingan padi di Indonesia memberikan konstribusi dalam penyediaan beras nasional baik dari segi kuantitas maupun kualitas dimana peranannya sebagai pusat pertemuan antara produksi, pengolahan dan pemasaran bagi padi Indonesia. Berdsarkan penelitian Ibrahim,2012 menyatakan bahwa usaha penggilingan padi memiliki keterkaitan kedepan dan ke belakang, dimana dikatakan bahwa usaha penggilingan padi memiliki nilai keterkaitan kedepan dan ke belakang paling tinggi dibandingkan agroindustri lainnya.

Desa Lombok Kulon Kecamatan Wonosari Kabupaten Bondowoso merupakan suatu desa yang masyarakatnya menerapkan sistem pertanian organik. Kelompok tani "Tani Mandiri 1" ini merupakan salah satu kelompok tani yang melakukan usaha tani padi atau beras organik. Produk beras organik diberi nama "Botanik". Beras organik "Botanik" memiliki gudang penggilingan padi dan pengemasan produk beras organik yang dikenal sebagai Unit Processing Padi Organik Tani Mandiri I. Unit Processing Padi Organik Tani Mandiri I dapat dikatakan masih tergolong baru yaitu kurang lebih sekitar 3 - 4 tahun. Keadaan ini memerlukan suatu analisis dan evaluasi sehingga usaha penggilingan tersebut layak beroperasi secara optimal. 
Tujuan dari penelitian ini yaitu (1) Untuk menganalisis struktur biaya finansial Unit Processing Padi Organik Tani Mandiri I dengan pendekatan evaluasi proyek di Desa Lombok Kulon Kecamatan Wonosari Kabupaten Bondowoso, (2) Untuk menganalisis kriteria kelayakan finansial Unit Processing Padi Organik Tani Mandiri I di Desa Lombok Kulon Kecamatan Wonosari Kabupaten Bondowoso dan (3) Untuk mengetahui tingkat sensitivitas perubahan biaya input (Biaya OM).

\section{METODE PENELITIAN}

Penelitian dilaksanakan di Desa Lombok Kulon, Kecamatan Wonosari, Kabupaten Bondowoso pada bulan Januari 2017. Pemilihan lokasi dilakukan secara sengaja (purposive sampling). Pemilihan lokasi penelitian dengan pertimbangan yaitu (1) Lokasi penelitian merupakan desa wisata organik dengan produk unggulannya yaitu beras organik dan merupakan satu - satunya wilayah yang memiliki luas lahan pertanian organik paling luas di Kabupaten Bondowoso serta telah mengantongi sertifikat organik (2) Dilihat dari beberapa tahun terakhir, permintaan beras organik "Botanik" semakin hari mengalami peningkatan.

Data yang digunakan dalam penelitian adalah data primer dan sekunder. Data primer berupa informasi tentang penggilingan padi yang diperoleh dari hasil pengamatan langsung, wawancara langsung secara terpadu dengan pemilik ataupun pengelola pabrik penggilingan padi organik.

Data sekunder diperoleh dari instansi - instansi terkait, seperti badan pusat statistik (BPS), Dinas Pertanian Kabupaten Bondowoso, internet, literature yang relevan seperti jurnal, buku, teks, majalah, surat kabar, dan sebagainya serta penelitian penelitian terdahulu yang dapat dijadikan bahan rujukan yang berhubungan dengan penelitian ini.

Pemilihan responden dilakukan dengan cara purposive sampling atau pemilihan secara sengaja dengan pertimbangan responden adalah aktor atau pengelola pabrik penggilingan (stakeholders) terdiri dari Dinas Pertanian, masyarakat, perbankan, gapoktan, pengurus atau ketua gapoktan, pengurus dan pengelola RMU. Pertimbangan pemilihan lokasi atau tempat penelitian yaitu karena alasan keterbatasan waktu, tenaga dan dana, sehingga tidak dapat mengambil tempat yang luas atau jauh.

Pertimbangan lain terkait pemilihan lokasi penelitian yaitu meskipun tergolong baru usaha beras organik "Botanik" banyak mengalami peningkatan yang drastis, maka dari itu peneliti tertarik untuk meneliti analisis kelayakan finansial Unit Processing Padi Organik Tani Mandiri I.

Metode yang digunakan dalam pengumpulan data adalah dengan wawancara langsung, wawancara mendalam dan observasi. Teknik pengumpulan data tersebut digunakan untuk mengumpulkan data primer. Data sekunder, teknik pengumpulan data dilakukan dengan cara studi literature dan browsing internet.

Data yang diperoleh dari hasil penelitian dikumpulkan dan diolah untuk dilakukan analisis lebih lanjut. Digunakan analisis deskriptif untuk mengetahui jumlah gabah yang diolah dan sumber gabahnya dengan menanyakan langsung kepada pemilik atau pengelola pabrik penggilingan beras organik.

Berdasarkan Pudjosumarto, 2008 menegaskan bahwa, perhitungan tingkat kelayakan di analisis dengan menggunakan metode analisis kelayakan yang berada dalam kriteria investasi yaitu net present value (NPV), net benefit cost ratio (Net B/C), internal rate of return (IRR) dan Payback Period $(P P)$ dengan rumus sebagai berikut yaitu : 


\section{Rumus NPV yaitu:}

$N P V=\sum_{t=0 / 1}^{t=n}($ Net benefit) $X \mathrm{DF}$

Dimana :

Net Benefit $\quad=$ Benefit - Cost

DF $\quad=$ Discount Fact

Kriteria yang digunakan:

NPV > 0, usaha layak untuk dijalankan

$\mathrm{NPV}=0$, usaha tersebut mengembalikan sama besarnya nilai uang yang ditanamkan. NPV $<0$, usaha tidak layak untuk dijalankan.

\section{Rumus Net B/C yaitu:}

$$
\text { NET } \frac{B}{C}=\frac{\text { NPV Positif }}{\text { NPV Negatif }}
$$

Dengan kriteria:

- Bila Net $\mathrm{B} / \mathrm{C}>1$, maka usaha tersebut layak dilaksanakan.

- Bila Net $\mathrm{B} / \mathrm{C}<1$, maka usaha tersebut tidak layak dilaksanakan.

\section{Rumus IRR yaitu:}

$\mathrm{IRR}=i_{1}+\frac{N P V 1}{N P V 1-N P V 2} X\left(i_{2}-i_{1}\right)$

Dimana :

$i_{2}=$ Discount rate yang menghasilkan NPV positif

$i_{1}=$ Discount rate yang menghasilkan NPV negative

$N P V_{1}=$ NPV positif

$N P V_{2}=\mathrm{NPV}$ negative

Dengan kriteria:

- Bila IRR > tingkat suku bunga berlaku, maka usaha tersebut layak dilaksanakan.

- Bila IRR < tingkat suku bunga berlaku, maka usaha tersebut tidak layak dilaksanakan.

4. Rumus Payback Period:

$$
\text { Payback Period }=\frac{\mathrm{I}}{\mathrm{Ab}}
$$

Dimana :

I = besarnya biaya investasi yang diperlukan.

$\mathrm{Ab}=$ benefit bersih yang dapat diperoleh pada setiap tahunnya.

\section{Rumus AB (Average Benefit):}

$$
\mathrm{Ab}=\frac{\Sigma \text { Benefit }-\Sigma O M}{\text { Umur Usaha }}
$$

5. Rumus Analisis Sensitivitas:

\section{Analisis Sensitivitas:}

$\%$ Perubahan Komponen X $\frac{100 \%}{\% \text { Perubahan NPV }}$ 


\section{Analisis Biaya}

\section{Biaya Investasi}

Unit Processing Padi Organik Botanik sudah beroperasi sekitar 4 tahun. Pabrik penggilingan beras organik "Botanik" mulai beroperasi sekitar tahun 2013 dengan mengeluarkan biaya investasi sebesar Rp 2.223.900.000. Biaya investasi ini terdiri dari pembangunan satu unit bangunan kantor yang sekaligus gedung penggilingan seluas 600 $\mathrm{m}^{2}$, pembuatan lantai jemur gabah, gedung dryer atau gedung pengeringan gabah seluas $300 \mathrm{~m}^{2}$ pembelian alat- alat produksi, fasilitas kantor dll. Rincian biaya dapat dilihat pada tabel 1 sebagai berikut:

\begin{tabular}{cccc}
\hline No & Uraian & Biaya $(\mathbf{R p})$ & Persentase \\
\hline $\mathbf{1}$ & Bangunan & $\mathbf{1 , 1 3 2 , 0 0 0 , 0 0 0}$ & \\
$\mathbf{2}$ & $\begin{array}{c}\text { Pembelian } \\
\text { Alat dan } \\
\text { Mesin }\end{array}$ & $\mathbf{1 , 0 9 1 , 9 0 0 , 0 0 0}$ & \\
& & &
\end{tabular}

\begin{tabular}{ccc} 
Jumlah & $\mathbf{2 , 2 2 3 , 9 0 0 , 0 0 0} 100$ \\
\hline Sumber: Data Primer Diolah, 2017
\end{tabular}

\section{Biaya Operasional dan Pemeliharaan}

Biaya operasional yang dikeluarkan Unit Processing Padi Organik Tani Mandiri I yaitu meliputi biaya pembelian gabah, tenaga kerja langsung, pajak bangunan, bahan bakar dll. Rata - rata biaya operasional dan pemeliharaan pada setiap tahunnya yaitu sebesar Rp. 2.288.931.250. Biaya operasional dan pemeliharaan terbesar yang dikeluarkan oleh Unit Processing Padi Organik Tani Mandiri I adalah biaya pembelian gabah (GKB).

\section{Biaya Tenaga Kerja}

Unit Processing Padi Organik Tani Mandiri I memiliki karyawan sebanyak 8 orang karyawan, yang terdiri dari 3 karyawan laki- laki yang bertugas mengatur mesin penggilingan beras, 3 orang karyawan bertugas mengatur proses pengeringan gabah kering baik menggunakan teknologi manual maupun menggunakan mesin dryer, 2 orang perempuan yang bertugas menyortir beras yang telah digiling agar kualitas beras selalu terjaga. Sistem pembayaran upah tenaga kerja yaitu dilakukan pembayaran secara harian, dengan jam kerja dimulai pukul 07.00 hingga pukul 16.00. Untuk tenaga kerja laki- laki diberi upah sebesar Rp. 50.000 per harinya, sedangkan untuk tenaga kerja perempuan diberi upah sebesar Rp. 30.000 per harinya. Rata - rata total biaya yang dikeluarkan pada setiap tahunnya yaitu sebesar Rp. 129.900.000.

\section{Benefit}

Benefit merupakan penerimaan yang diperoleh dari hasil penjualan 3 jenis beras organik yaitu beras merah, beras hitam, dan beras putih. Selain produk utama beras organik, Unit Processing Padi Organik Tani Mandiri I juga menjual limbah pabrik seperti sekam, menir, dan bekatul. Rata - rata pendapatan per tahun yaitu sebesar Rp 3.919.206.710.

\section{Analisis Kelayakan Finansial}

Kriteria yang digunakan untuk mengetahui kelayakan tersebut adalah NPV, Net B/C Ratio, IRR, Payback Period dan Analisis Sensitivitas. Dalam Penelitian ini discount rate sebesar $7 \%$, selanjutnya untuk mengetahui nilai sekarang digunakan data present value. 


\section{Net Present Value (NPV)}

Nilai PVB , PVOM, dan PVI yang diperoleh pada Unit Processing Padi Organik Tani Mandiri I adalah sebagai berikut yaitu PVB sebesar Rp. 13.274.353.127,00, PVOM sebesar Rp. 9.676.015.775,00 dan PVI sebesar Rp. 2.223.968.670,00 dengan DF sebesar 7\%. Perhitungan PVB diperoleh dari akumulasi benefit mulai tahun ke 0 sampai tahun ke 4, begitu juga dengan PVOM dan PVI. Namun dalam menghadapi time value of money maka dikalikan dengan DF sebesar 7\% yang sudah ditetapkan dalam pengevaluasian proyek Unit Processing Padi Organik Tani Mandiri I. Maka dari itu, untuk mendapatkan nilai NPV menggunakan rumus : NPV $=$ PVB - PVOM - PVI

NPV $\quad=13.274 .353 .127-9.676 .015 .775-2.223 .968 .670$ $=1.374 .368 .682$

Nilai NPV pada tabel 8 dengan discount rate $7 \%$ berdasarkan pertimbangan ratarata suku bunga acuan Bank Indonesia mulai tahun 2013 - 2016, diperoleh nilai NPV sebesar Rp. 1.374.368.682

\section{Internal Rate of Return (IRR)}

IRR dapat dihitung dengan menggunakan rumus:

$$
I R R=i_{1}+\frac{N P V 1}{N P V 1-N P V 2} X\left(i_{2}-i_{1}\right)
$$

NPV 1 = Nilai NPV pada Df 6\%

NPV $2=$ Nilai NPV pada Df 7\% IRR $=6 \%+\frac{1.456 .180 .006}{1.456 .180 .006-1.374 .368 .682} X(7 \%-6 \%)$

$I R R=6 \%+\frac{1.456 .180 .006}{81.811 .324} X 1 \%$

IRR $=6 \%+17,80 \times 1 \%$

IRR $=23,80 \%$

Perhitungan nilai IRR menggunakan DF1 sebesar 6\% yang diperoleh dari rata rata suku bunga acuan Bank Indonesia pada tahun 2013, sedangkan DF2 sebesar $7 \%$ yang diperoleh dari rata - rata suku bunga acuan Bank Indonesia tahunan mulai tahun 2013 2016. Analisis finansial Unit Processing Padi Organik Tani Mandiri I diperoleh nilai IRR sebesar 23,80\% lebih besar dari suku bunga yang telah ditetapkan yaitu $7 \%$ menunjukkan bahwa investasi Unit Processing Padi Organik Tani Mandiri I ini dapat dijalankan, ini menunjukkan ketika suku bunga meningkat sampai 23,80\%, Unit Processing Padi Organik Tani Mandiri I layak dijalankan.

3. Payback Period (PP)

Perolehan payback period menggunakan rumus sebagai berikut:

Payback Period $=\sum \mathbf{I} / \mathbf{A b}$

$$
\begin{aligned}
& \mathrm{Ab}=\frac{\text { Ebenefit }-\Sigma O M}{\text { Umur Usaha }} \\
& \mathrm{Ab}=\frac{15.676 .826 .840-9.120 .000 .000}{4} \\
& \mathrm{Ab}=1.639 .206 .710
\end{aligned}
$$

Payback Period $=\frac{2.223 .990 .000}{1.639 .206 .710}$

$$
\begin{aligned}
& =1,357 \\
& =1,4(\text { dibulatkan })
\end{aligned}
$$


Berdasarkan perolehan hasil payback period tersebut dapat disimpulkan bahwa modal awal yang digunakan untuk investasi akan kembali atau dalam kondisi impas yaitu 1 tahun 4 bulan .Sehingga dapat dihitung bahwa nilai investasi akan kembali pada kisaran tahun kedua produksi dimulai.

\section{Net B/C Ratio}

Untuk mendapatkan nilai Net B/C ratio dapat diformulasikan dengan rumus sebagai berikut:

\section{Rumus Net B/C yaitu:}

$$
\text { Net } \begin{aligned}
\mathrm{B} / \mathrm{C} \text { Ratio } & =\frac{3.598 .268 .682}{2.223 .900 .000} \\
& =1,62
\end{aligned}
$$

$$
\text { NET } \frac{B}{C}=\frac{\text { NPV Positif }}{\text { NPV Negatif }}
$$

Berdasarkan perhitungan Net B/C ratio diatas diketahui nilai Net B/C Ratio sebesar 1,62. Jadi, dapat disimpulkan bahwa Unit Processing Padi Organik Tani Mandiri I layak dijalankan karena nilai Net B/C Ratio > 1 .

\section{Analisis Sensitivitas}

Hasil Perhitungan diperoleh, bahwa kenaikan biaya OM sebesar 14,20\% dari perhitungan biaya yang telah ditetapkan dapat menyebabkan NPV menjadi 0 , hal ini berarti Unit Processing Produksi Padi Oganik Tani Mandiri I tidak terlalu sensitif terhadap adanya kenaikan biaya solar.

\section{KESIMPULAN}

Bedasarkan dari hasil analisis finansial pada Unit Processing Padi Organik Tani Mandiri I dapat ditarik kesimpulan sebagai berikut:

1. Unit Processing Padi Organik Tani Mandiri I sangat layak dijalankan berdasarkan analisis kelayakan finansial, hal ini dibuktikan dengan hasil analisis data dengan menggunakan analisa NPV, Net B/C, dan IRR.

2. Pada perhitungan payback period diperoleh nilai sebesar 1,4 tahun, jadi nilai ini menunjukkan bahwa seluruh biaya investasi yang dikeluarkan untuk Unit Processing Padi Organik Tani Mandiri 1 akan dapat dikembalikan pada tahun ke 2, karena nilai payback period dari Unit Processing Padi Organik Tani Mandiri 1 lebih kecil dari pada umur usaha sehingga layak untuk dijalankan.

3. Berdasarkan hasil analisis sensitivitas terhadap OM diperoleh nilai sebesar $14,20 \%$, yang berarti usaha ini tidak terlalu sensitif terhadap kenaikan atau perubahan biaya OM terutama harga solar.

\section{Saran}

1. Unit Processing Padi Organik Tani Mandiri 1 didukung oleh ketersediaan bahan baku yang cukup besar dan penggunaan biaya produksi yang efisien, namun belum memenuhi permintaan beras yang semakin hari semakin meningkat makan dari itu perlu dilakukan peningkatan skala produksi untuk mengoptimalkan bahan baku yang tersedia.

2. Perlu adanya peningkatan pemasaran produk seperti menambah retail penjualan beras organik "Botanik" khususnya di daerah Kabupaten Bondowoso. 
ISSN : -

Volume: 01 Number: 01

\section{DAFTAR PUSTAKA}

Ibrahim, Jabal Tarik, Aris Soelistyo, Sutikno.2012. Pengembangan Agroindustri Jawa Timur. UMM Press: Malang

Pudjosumarto, Muljadi. 2008. Evaluasi Proyek. Malang : Liberty Yogyakarta.

Sriyanto, Sugeng. 2010. Panen Duit Dari Bisnis Padi Organik. Jakarta Selatan : Agromedia Pustaka. 